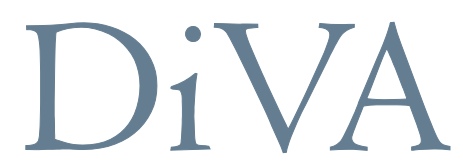

http://uu.diva-portal.org

This is an author produced version of a paper published in Journal of Philosophical Logic. This paper has been peer-reviewed but does not include the final publisher proof-corrections or journal pagination.

Citation for the published paper:

Kent Hurtig

"On Prima Facie Obligations and Nonmonotonicity"

Journal of Philosophical Logic, 2007, Vol. 36, Issue 5, pp. 599-604

URL: http://dx.doi.org/10.1007/s10992-007-9056-0

Access to the published version may require subscription. 


\section{On Prima Facie Obligations and Nonmonotonicity}

In their introduction to Defeasible Deontic Logic ${ }^{1}$ Donald Nute and Xiaochang Yu write:

A defeasible deontic logic may not only solve some of the familiar paradoxes of deontic logic, but may actually be attractive to moral philosophers, jurists, and others who would seem to be the natural clients of the deontic logician. ${ }^{2}$

I agree that a defeasible (or nonmonotonic) deontic logic may help solve some of the so-called paradoxes of deontic logic. I doubt, however, that moral philosophers are the natural clients of the deontic logician; on the contrary, given what Nute and Yu go on to claim next, it seems some deontic logicians ought to be the clients of the moral philosopher. They say:

The very expression prima facie obligation cries out for a defeasible or nonmonotonic analysis. Such an obligation binds unless it is overridden by appropriate considerations - usually a higher obligation.

This is not so however. Although there may be good reasons for developing nonmonotonic deontic logics, considerations relating to prima facie obligations do not provide such reasons. So insofar as the motivation to develop nonmonotonic deontic logics stems from such considerations, to this extent such logics are not well 
motivated. The temptation to develop nonmonotonic logics for normative reasoning, I believe, stems from a confusion about such concepts as prima facie duties, proper (or actual) duties, and pro tanto reasons and the relations between these concepts. Before I can show why this is so, I need to say something about monotonicity. The concept is clearly explained by John Horty:

[Monotonicity $=$ ] ... if $\mathrm{A}$ is a consequence of $\Gamma$, then $A$ is a consequence of $\Gamma \cup\{B\}$. What this means is that any conclusion drawn from a set of premises will be preserved as a conclusion even if the premise set is supplemented with additional information - that the set of conclusions grows monotonically as the premise set grows. ${ }^{3}$

A nonmonotonic logic, then, is a logic in which we are not entitled to say that if A is a consequence of $\Gamma$, then $A$ is a consequence of $\Gamma \cup\{B\}$. Or, to put it more simply, nonmonotonic logics do not allow what is commonly referred to as 'strengthening of the antecedent'.

So why might it be thought that a logic of prima facie obligations demands a nonmonotonic structure? In the current literature, it is widely accepted among moral philosophers (I dare say) that the idea of a prima facie obligation admits only of two reasonable interpretations. Prima facie obligations are either

(a) apparent obligations (which may or may not on closer inspection turn out to be genuine obligations), or

(b) pro tanto reasons. 
On neither of these interpretations do prima facie obligations obviously demand, much less 'cry out' for, a defeasible or nonmonotonic analysis. On the first interpretation, if a prima facie obligation - conceived of as an apparent obligation turns out not to be a genuine obligation, it does not cry out for an analysis at all - or at least not a philosophical analysis (although sociologists, psychologists, and historians etc. may have something interesting to say about these phenomena). If we manage to show that the obligation is genuine, however, it simply ceases to be a prima facie obligation. In this sense of prima facie, a prima facie obligation is, roughly, an 'obligation proposition' whose truth-value we are simply uncertain of.

At any rate, I doubt this is the kind of prima facie obligation Nute and $\mathrm{Yu}$ have in mind. They seem to suggest that prima facie obligations should be understood in roughly the same way W. D. Ross ${ }^{4}$ has traditionally been interpreted as understanding them. Ross says:

I suggest 'prima facie' duty or 'conditional duty' as a brief way of referring to the characteristic (quite distinct from that of being a duty proper) which an act has, in virtue of being of a certain kind (e.g. the keeping of a promise), of being an act which would be duty proper if it were not at the same time of another kind which is morally significant. ${ }^{5}$

There is good reason, however, to believe that what Ross meant by a prima facie obligation, is what moral philosophers today refer to as a pro tanto reasons, and I shall discuss these later. Before I do so I want to say something more about Nute and Yu's formulation of prima facie obligations. 
If, as they suggest, a prima facie obligation binds unless it is overridden by some other obligation, why can we not treat these in the same way we treat ordinary 'unless' claims, where these in turn are treated monotonically? Well, we might be able to once we find out what prima facie obligations are supposed to be on this understanding of them. Consider first 'A has a prima facie obligation to pay his taxes.' How should we understand this claim in light of Nute and Yu's formulation of prima facie obligations? Should we understand it as

$$
\begin{aligned}
& \text { A has a prima facie obligation to pay his taxes unless } \\
& \text { he has a prima facie obligation not to pay his taxes which is such that } \\
& \text { it overrides his prima facie obligation to pay his taxes? }
\end{aligned}
$$

This can't be right. (1) is logically equivalent to

$$
\begin{aligned}
& \text { If it is not the case that A has a prima facie obligation } \\
& \text { to pay his taxes then he has a prima facie obligation not to pay his } \\
& \text { taxes which is such that it overrides his prima facie obligation to pay } \\
& \text { his taxes. }
\end{aligned}
$$

The consequent of $\left(1^{*}\right)$ says that A has a prima facie obligation not to pay his taxes which is stronger than A's obligation to pay them. But A's prima facie obligation not to pay his taxes can override his prima facie obligation to pay his taxes only if he really has a prima facie obligation to pay his taxes - which the antecedent says he doesn't have. So (1) leads to contradiction: If it is not the case that A has a prima facie obligation to pay his taxes then he has a prima facie obligation to pay his taxes. 
So we should not understand prima facie duties or obligations in the way (1) specifies.

Perhaps we should understand the idea of a prima facie obligation as

(2) If A has a prima facie obligation to pay his taxes, then unless he has a stronger prima facie obligation not to pay his taxes, he has an obligation proper to pay his taxes.

This seems right. Of course, this is not meant to be a definition of a prima facie obligation, and given my aims in this paper, I do not need supply such a definition. If (2) is correct, there is good reason to believe that prima facie obligations are nothing over and above pro tanto reasons, where 'pro tanto' means, roughly, 'as far as that goes'.

Now, a very strong case can be made for saying that pro tanto reasons are defeasibly ought-making in the sense that you ought to act on a consideration which provides you with a pro tanto reason unless some other consideration provides you with a stronger pro tanto reason not to so act. As a matter of fact, this is exactly what (2) says. This does not imply, however, that pro tanto reasons are in themselves defeasible, or that a logic of pro tanto reasons - or indeed of 'ought' - must be nonmonotonic. On the contrary, since 'pro tanto' means 'as far as that goes', if $\mathrm{F}$ is (or provides) A with a pro tanto reason to $\varphi$, this means that A has $a$ reason (as far as F goes - as we might put it) to $\varphi$ regardless of whether there are other reasons (i.e. other than the one provided by F) to $\psi$ or not to $\psi$. Although reasons do not in and of themselves 'bind' in terms of being 'ought-making', reasons bind normatively in 
another, quite trivial, way: they make it true of you that you have a reason to do the thing in question, and they do this in their own right.

Strictly speaking, pro tanto reasons are probably best understood as relations, the relata of which are facts, agents and actions: the fact that you will disappoint her if you $\varphi$ gives you a reason not to $\varphi$. Reasons may of course be outweighed ${ }^{6}$, or defeated, or overridden, by other reasons (or sets of reasons) with respect to what ought to be done - or, as it is sometimes put, with respect to what one's obligation or duty proper is - but this is not the same kind of defeasibility which is associated with nonmonotonicity. ${ }^{7}$ To illustrate the point: Suppose I have promised Davey to meet him at Aikman's Bar and Bistro at eight o'clock. My having made this promise gives me (we may assume) a reason to go to Aikman's at eight. However, on the way to Aikman's I come across a terrible traffic accident and I alone am able to help the victims. The fact that these people need my help provides me with a reason to stop and help them which is such that it is stronger than the reason I have for going to Aikman's. Absent any further reasons for going to Aikman's, it is not the case that I ought to meet Davey at Aikman's. This does not mean, however, that I no longer have any reason to go and meet him. I do. I still have a reason to met him, it's only that this reason has been overridden by the stronger reason I have to help the accident victims. $^{8}$

I should admit that all this may not be as clear cut as I've made it out to be. After all, those who subscribe to a particularist view of (at least practical) reasons typically do so because they believe that reasons for action are indeed defeasible in the sense I have just denied that they are. I think particularism about reasons is false, but even if I am mistaken about this, it is still false, or at least seriously misleading to claim, that "the very expression prima facie obligation cries out for a...nonmonotonic 
analysis.' Whether or not reasons for action are themselves defeasible (suitably construed) is a substantive issue which must be settled in the theory of practical reason; it is not something that can be settled (or even motivated by) the observation that there is some sort of overridingness going on in normative reasoning.

To repeat: reasons are indeed defeasible by other reasons with respect to what ought (overall) to be done, but this does not mean that a conditional like

(3) If the fact that $\mathrm{F}$ gives $\mathrm{A}$ a reason (gives $\mathrm{A}$ a prima facie obligation) to $\varphi$, then F gives A has a reason (gives A a prima facie obligation) to $\varphi$.

doesn't 'bind', or that it should be subject to a nonmonotonic analysis. (3) is a necessary truth, and no amount of adding additional information to the antecedent will make (3) false. Compare this to:

(4) If the fact that $\mathrm{F}$ gives $\mathrm{A}$ a pro tanto reason (gives A a prima facie obligation) to $\phi$, then A ought (has a duty proper) to $\phi$.

(4) is certainly not a necessary truth; there are many instances of it that are false. The fact that one has a reason to $\phi$ does not imply that one ought to $\phi$. Rather, the correct relation between reasons - and hence prima facie obligations - and oughts is given by (2). Putting (2) in terms of reasons and ought, we get

$\left(2^{*}\right) \quad$ If $\mathrm{A}$ has a reason to $\varphi$ and it is not the case that A has a stronger reason not to $\phi$, then A ought to $\phi .^{9}$ 
There is no reason to think that formulae like $\left(2^{*}\right)$ have a nonmonotonic structure.

My guess is that the idea that prima facie obligations 'cry out' for a defeasible analysis results from the mistaken idea that something like (4) - whether formulated in terms of prima facie obligations or pro tanto reasons - displays the correct relation between reasons and oughts. Were this to be so, a nonmonotonic logic of normative reasoning would certainly be called for. However, (4) and other instances like it, are not true, and, save particularist worries, there are no good reasons to believe that normative concepts demand a nonmonotonic treatment.

${ }^{1}$ Donald Nute (ed) (Dordrecht: Kluwer Academic Publishers, 1997).

${ }^{2}$ Ibid., p. 1.

${ }^{3}$ John F. Horty, 'Nonmonotonic Logic' in Lou Goble (ed.) The Blackwell Guide to Philosophical Logic (Malden, Mass: Blackwell Publishers, 2001), p. 336.

${ }^{4}$ See Ross' The Right and the Good (Oxford: Oxford University Press, 1930), especially pp 16-47.

5 Ibid., p. 19.

${ }^{6}$ In fact, John Broome has recently argued that pro tanto reasons are defined by the particular role they play in what he calls 'weighing explanations' of why we ought to do a certain thing. See his 'Reasons' in Reason and Value: Essays on the Moral Philosophy of Joseph Raz, edited by Jay Wallace, Michael Smith, Samuel Scheffler and Philip Pettit (Oxford: Oxford University Press, 2004), pp 28-55.

${ }^{7}$ For the most recent discussion and defence of particularism in the theory of reasons, see Jonathan Dancy's Ethics without Principles (Oxford: Oxford University Press, 2004). For an excellent collection of essays on various kinds of particularism in moral philosophy, see Brad Hooker and Margaret Little (eds) Moral Particularism (Oxford: Clarendon Press, 2000). In what follows, I shall speak only of 'reason(s)' and take pro tanto as read.

${ }^{8}$ Furthermore, although it is hard to put the point precisely, it seems plausible to say that the reason I have to meet Davey at Aikman's is 'converted' into a reason to eventually explain (as opposed to apologise) to him why I didn't show up at eight o'clock. It would be hard to explain why I have this reason to explain my absence if 
the original reason I had to meet him at the pub did not somehow retain its normative force.

${ }^{9} \mathrm{We}$ may also need to add a third conjunct to the antecedent: 'and it is not the case that $\mathrm{A}$ has some reason not to $\phi$ which is such that its strength is equal to the reason he has to $\phi '$. Because if the reasons for and against $\phi$-ing are equally strong, it is far from clear that A ought to $\phi$. In what follows I shall ignore this complication. 